\title{
TÍNH TOÁN KHẢ NĂNG TIẾP NHẬN CHÂT Ô NHIỄM CỦA ĐÂM THỊ NẠI (TỈNH BÌNH ĐỊNH)
}

\author{
Cao Thị Thu Trang*, Vũ Duy Vĩnh \\ Viện Tài nguyên và Môi truờng biển-Viện Hàn lâm Khoa học và Công nghệ Việt Nam \\ E-mail: trangct@imer.ac.vn
}

Ngày nhận bài: 5-8-2015

\begin{abstract}
TÓM TĂT: Dựa trên các số liệu khảo sát về chất luợng nước tại đầm Thị Nại mùa mưa (tháng 10/2013) và mùa khô (tháng 5/2014), các tài liệu thu thập về điều kiện tụ nhiên, kinh tế - xã hội ven đầm và các tiêu chuẩn môi truờng, đã tính toán khả năng tiếp nhận các chất ô nhiếm trong đầm thông qua sử dụng mô hình Delft3D. Kết quả tính cho thấy, hiện tại đầm Thị Nại không còn khả năng tiếp nhận amoni, nitrat. Tới năm 2025, ngoài 2 thông số này đầm Thị Nại sẽ không còn khả năng tiếp nhận phosphat. Ngoài ra, khả năng tiếp nhận của đầm sẽ giảm đi đối với hầu hết các thông số (3,44\%, 1,84\%, 0,02\%, 12,18\%, 0,46\% đối với $\mathrm{COD}, \mathrm{Cu}, \mathrm{Pb}, \mathrm{Zn}$ và As, tương ứng), trong khi khả năng tiếp nhận $B O D_{5}$ và vật lơ lưng tăng lên. Liên quan đến các kim loại nặng, khả năng tiếp nhận của đầm cũng giảm đi nhiều nhất là Zn $(12,18 \%)$.
\end{abstract}

Tù khóa: Lương chất ô nhiễm, khả năng tiếp nhận, đầm Thị Nại.

\section{Mở ĐẦU}

Một thủy vực được phép tiếp nhận một lượng chất thải (chất ồ nhiễm) nhất định sao cho chất lượng nước không vi phạm các tiêu chuẩn môi trường hiện hành của quốc gia đó. Lượng chất được phép tiếp nhận này được tính toán phụ thuộc vào tỷ lệ trao đổi nước của thủy vực với khu vực liền kề (biển, sông ...) và các tiêu chuẩn môi trường. Dựa trên các kết quả tính toán này có thể đề ra các định mức phát thải. Ở các nước đang phát triển, việc tính toán khả năng tiếp nhận của một thủy vực ngày càng được quan tâm do sự phát triển nhanh chóng của kinh tế - xã hội. Ví dụ tại Trung Quốc, việc tăng trưởng kinh tế thiếu kiểm soát đã đặt quốc gia này ở trạng thái báo động về chất lượng môi trường [1]. Rầt nhiều nghiên cứu [2-6] về khả năng tiếp nhận và sức tải môi trường được thực hiện trong những năm gần đây ở Trung Quốc cho ta thấy các nước đang phát triển (trong đó có Việt Nam) đang và sẽ phải đối mặt với các vấn đề môi trường. Enhui và nnk.,
(2013) [2] đã tính toán 3 phương án để giảm thiểu nồng độ phosphat trong nước vịnh Hạ Môn (Trung Quốc) từ $0,06 \mathrm{mg} / \mathrm{l}$ xuống mức tiệu chuẩn quốc gia là $0,03 \mathrm{mg} / 1$, trong đó chủ yếu dựa trên việc giảm $67-74 \%$ tải lượng thải và phân bổ lại lượng thải của 22 nguồn thải đổ vào vịnh. Tại vịnh Jinzhou (Trung Quốc), khả năng tiếp nhận của $\mathrm{Zn}$ và $\mathrm{Cd}$ xấp xỉ là 17 và 8 tấn/tháng và̀ tổng tải lượng thải tối đa (TMAL - Total Maximum Allocated Loads) được phân bổ của $\mathrm{Zn}$ và $\mathrm{Cd}$ là 4 và 1,7 tấn/tháng [3]. Như vậy, tính toán khả năng tiếp nhận chât thải của thủy vực luôn có ý nghĩa trong cả trường hợp thủy vực đã bị ô nhiễm, đây chính là cơ sở để giảm nguồn phát thải.

Đầm Thị Nại là đầm lớn thứ hai ở Việt Nam, có cửa thông ra vịnh Quy Nhơn. Đầm có chiều dài khoảng $12 \mathrm{~km}$, chiều rộng khoảng $4 \mathrm{~km}$, độ sâu trung bình là $2,37 \mathrm{~m}$. Đầm là nơi tiếp nhận chất thải của cả thành phố Quy Nhơn và các xã thuộc huyện Phù Cát và huyện Tuy Phước. Các nguồn phát sinh chất thải vào đầm 
bao gồm chất thải từ dân cư sinh sống quanh đầm, chất thải công nghiệp của thành phố Quy Nhơn, chất thải chăn nuôi, nuôi trồng thủy sản và từ trên các lưu vực sông Kôn, sông Hà Thanh đổ ra [7,8]. Các nghiên cứu về chất lượng môi trường trong hơn chục năm trở lại đây cho thấy nước đầm Thị Nại có nồng độ chất hữu cơ, nồng độ muối dinh dưỡng và vật lơ lửng khá cao $[9,10]$, thậm chí vượt giới hạn cho phép đối với nước biển ven bờ dùng cho mục đích bảo vệ đời sống thủy sinh. Trên quan điểm phòng ngừa ô nhiểm, bài báo này trình bày kêt quả tính toán lượng chất ô nhiễm trong khối nước và khả năng tiếp nhận chất ô nhiễm ở đầm Thị Nại, nhằm giúp cho các nhà quản lý có cơ sở khoa học khi đưa ra các quyêt định phát triển kinh tế - xã hội của khu vực.

\section{TÀI LIỆU VÀ PHƯƠNG PHÁP NGHIÊN CúU}

\section{Tài liệu}

Tài liệu sử dụng cho bài báo được lấy từ các nguồn sau:

\section{Các số liệu khảo sát của đề tài KC09.17/11-15}

Số liệu hiện trạng môi trường nước đầm Thị Nại năm 2013-2014 trong hai mùa mưa $(10 / 2013)$ và mùa khô $(5 / 2014)$ vào thời kỳ triều cường và triều kém: 19 trạm khảo sát mặt rộng (ký hiệu TN) được thiết kế để đánh giá hiện trạng môi trường nước trong đầm.

Số liệu thực hiện các thí nghiệm ngoài hiện trường mùa mưa năm 2013 và mùa khô năm 2014, bao gồm: thí nghiệm đánh giá khả năng phân hủy vật chất trong nước, thí nghiệm đánh giá khả năng lắng đọng vật chất từ nước xuống trầm tích đáy, thí nghiệm đánh giá khả năng quang hợp của thực vật nổi và thí nghiệm đánh giá mức độ rửa giải vật chất từ trầm tích vào khối nước [11]. Hệ số của các thí nghiệm được sử dụng trong việc mô phỏng mô hình chất lượng nước.

Số liệu khảo sát liên tục thủy văn và chất lượng nước tại 2 vị trí giữa đầm (TNLT 1) và cửa đầm (TNLT 2) vào mùa mưa 2013 và mùa khô 2014.

Số liệu khảo sát nguồn thải tại một số vị trí xả nước thải vào đầm.
Sơ đồ trạm vị thu mẫu tại đầm Thị Nại được trình bày trong hình 1 .

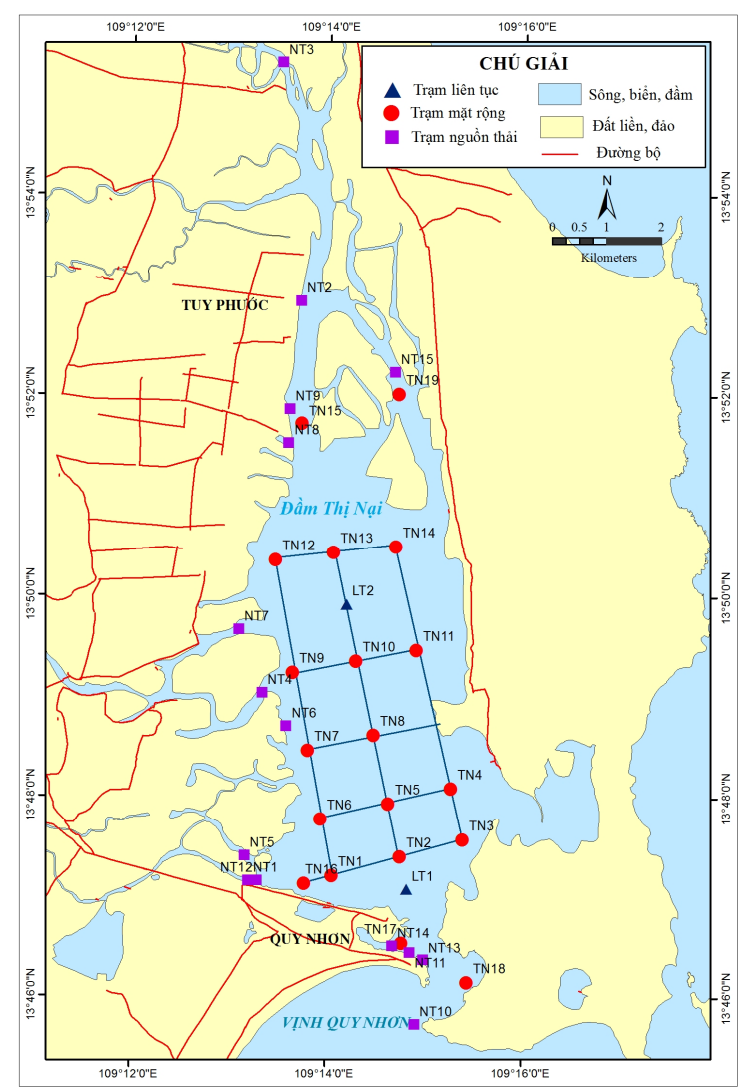

Hình 1. Sơ đồ thu mẫu chất lượng nước và vị trí các trạm thí nghiệm, trạm liên tục tại đầm Thị Nại

\section{Các tài liệu khác}

Các tài liệu thu thập từ các đề tài, dự án liên quan về chất lượng môi trường nước, trầm tích, hàm lượng các chất dinh dưỡng, năng suất sơ cấp của sinh vật phù du, nguôn thải chất ô nhiễm ở khu vực đầm Thị Nại [8-16].

Số liệu độ sâu và đường bờ của khu vực phía trong đầm Thị Nại và vùng biển ven bờ Quy Nhơn được số hóa từ các bản đồ địa hình UTM hệ tọa độ địa lý VN 2000 tỷ lệ 1:50.000 và $1: 25.000$. Độ sâu của khu vực phía ngoài sử dụng cơ sở dữ liệu GEBCO $-1 / 8$ có độ phân dải 0,5 phút được xử lý từ ảnh vệ tinh kêt hợp với các số liệu đo sâu [17, 18].

Các số liệu khí tượng: số liệu khí tượng được sử dụng là các kết quả đo đạc trong nhiều năm của trạm khí tượng Quy Nhơn. 
Số liệu cung cấp cho các biên nhiệt-muối của mô hình phía biển được thu thập từ cơ sở dữ liệu WOA09 [19] cho khu vực Biên Đông.

Các số liệu cho điều kiện biên mở: Số liệu thủy triều tại các biên mở phía biển là những hằng số điều hoà thủy triều. Các hằng số điều hoà thủy triều được tính toán từ chuồi số liệu quan trắc mực nước trong khoảng thời gian dài trong một số đề tài, dự án của Trung tâm Khí tượng Thuỷ văn biển, Phân viện Cơ học biển, Viện Tài nguyên và Môi trường biển, Viện Địa lý ... Những điểm biên lỏng phía biển không có số liệu quan trắc thì số liệu từ cơ sở dữ liệu các hằng số điều hòa thủy triều FES2004 [20, 21] của LEGOS (Laboratoire d'Etude en Géophysique et Océanographie Spatiales, Toulouse) và CLS (Collecte Localisation Satellites) thuộc Trung tâm Quốc gia nghiên cứu không gian Pháp (CNES Centre National d'Etudes Spatiales) nghiên cứu phát triển được sử dụng.

\section{Phương pháp nghiên cứu}

Mô hình thủy động lực - chất lượng nước (mô hình Delft3D [22]) để mô phỏng các điều kiện thủy động lực, lan truyền các chẩt ô nhiễm ở khu vực nghiên cứu được áp dụng.

\section{Mô hình thủy động lục}

Phạm vi và luới tính của mô hình

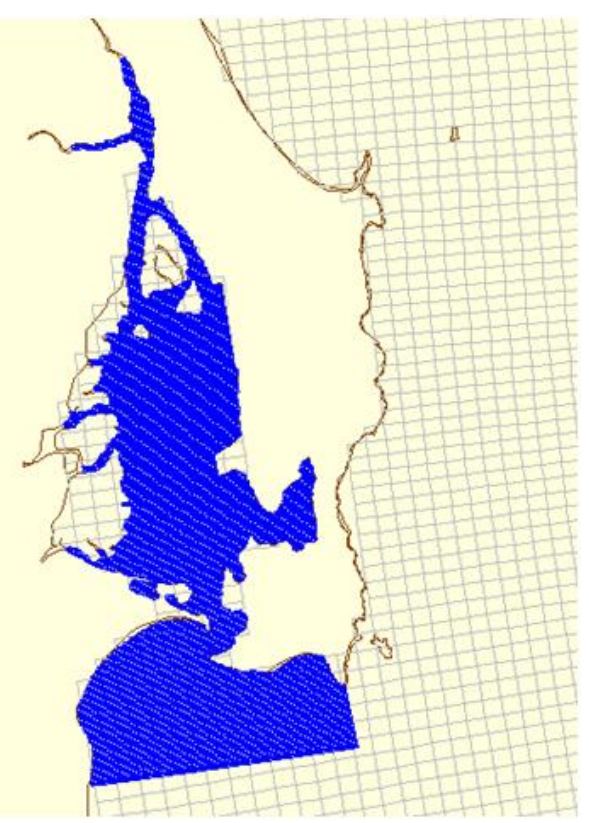

Hình 2. Lưới tính của mô hình thủy động lực khu vực đầm Thị Nại và phía ngoài
Lưới tính của mô hình thủy động lực cho khu vực đầm Thị Nại (lưới chi tiết) sử dụng hệ lưới cong trực giao. Phạm vi vùng tính của mô hình này bao phủ toàn bộ khu vực đầm Thị Nại và mở rộng ra phía ngoài biển với lưới tính thô hơn (hình 2). Miền tính này có kích thước khoảng $9 \mathrm{~km}$ theo phương đông bắc - tây nam, và $12 \mathrm{~km}$ theo phương tây bắc - đông nam, diện tích mặt nước khoảng $62,9 \mathrm{~km}^{2}$ được chia thành $113 \times 390$ điểm tính với các ô lưới có kích thước biến đổi từ $42 \mathrm{~m}$ đến $79 \mathrm{~m}$. Lưới tính theo chiều thẳng của mô hình này cũng được chia thành 5 lớp nước với tỷ lệ đều nhau từ mặt xuống đáy là $20 \%$.

Số liệu độ sâu của các mô hình phía ngoài và đầm Thị Nại được xử lý trên cơ sở địa hình và lưới đã được xây dựng (hình 3).
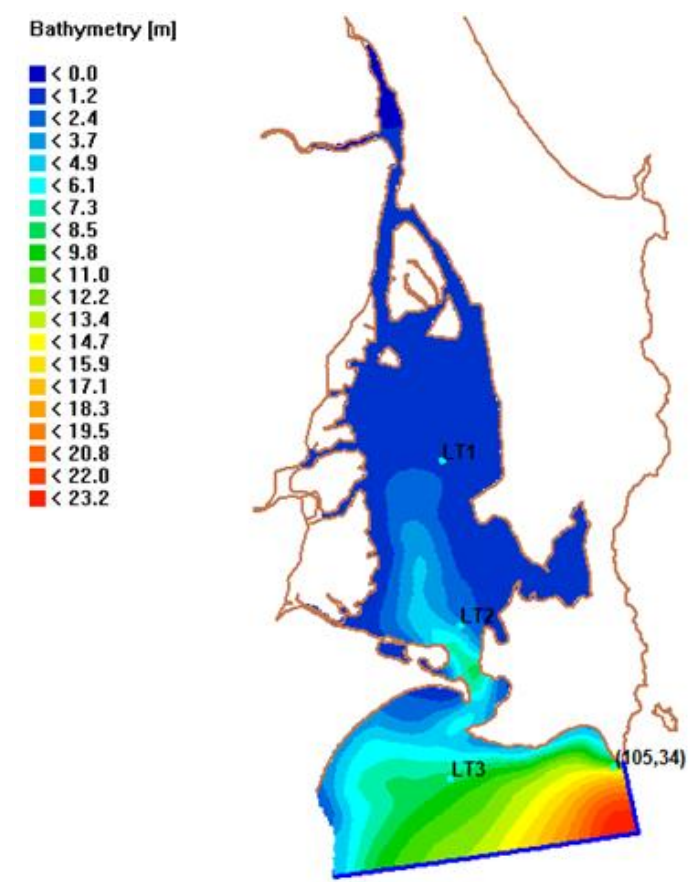

Hình 3. Lưới độ sâu cho mô hình lưới chi tiết khu vực đầm Thị Nại

\section{Điều kiện biên}

Mô hình lưới tính chi tiết có các biên mở phía biển như trên hình 2 . Điều kiện biên cho các biên này là kết quả tính từ mô hình lưới thô ở phía ngoài. Đó là các kết quả nhiệt độ, độ muối và dao động mực nước.

Thờ gian tính toán 
Mô hình được thiết lập tính cho các mùa đặc trưng trong năm: mùa mưa (tháng 9-10 năm 2013) và mùa khô (tháng 4-5 năm 2014). Bước thời gian chạy của mô hình là 0,1 phút.

Điều kiện ban đầu của các kịch bản hiện trạng là các kết quả tính toán sau ngày cuối trong các file restart của tháng 9 (mùa mưa) và tháng 4 (mùa khô).

\section{Hiệu chỉnh, kiểm chứng kết quả tính của mô hình}

Các kết quả tính toán của mô hình đã được kiểm chứng thông qua việc so sánh với số liệu quan trắc. So sánh kết quả tính toán mực nước từ mô hình với mực nước quan trắc tại Quy Nhơn cho thấy khá phù hợp kể cả về pha và biên độ. Sai số bình phương trung bình giữa tính toán và đo đạc mực nước ở các trạm này này dao động trong khoảng $0,13-0,14 \mathrm{~m}$.

Các giá trị quan trắc dòng chảy được phân tích thành các thành phần kinh hướng $(\mathrm{u})$ và vĩ hướng (v) trước khi so sánh với các kết quả tính toán từ mô hình. Sau lần hiệu chỉnh cuối cùng, kết quả so sánh cho thấy có sự phù hợp tương đối giữa số liệu đo đạc và tính toán chảy ở khu vực này.

\section{Mô hình chất lượng nước}

Mô hình chất lượng nước cho khu vực đầm Thị Nại được thiết lập dựa trên các kết quả tính toán mô phỏng từ mô hình thủy động lực. Đó là các kết quả:

Phạm vi miền tính, lưới tính, độ sâu của thủy vực;

Kết quả tính dao động mực nước, biến đổi độ sâu theo thủy triều của cột nước khu vực tính toán;

Kết quả tính và biến động theo thời gian của trường dòng chảy theo các lớp độ sâu;

Kết quả tính phân bố và biến động theo không gian và thời gian của các trường nhiệt độ - độ muối.

Các đối tượng tính toán mô phỏng: Nhóm hữu cơ $\left(\mathrm{BOD}_{5}, \mathrm{COD}\right)$; Nhóm các chất dinh dưỡng của Nitơ $\left(\mathrm{NH}_{4}, \mathrm{NO}_{3}\right)$, phosphate $\left(\mathrm{PO}_{4}\right)$ và vật lơ lửng (TSS).

Thời gian tính toán mô phỏng: Các kịch bản tính toán cho kịch tính cho điều kiện hiện trạng được chia làm 2 mùa mưa (10/2013) và khô (5/2014). Bước thời gian cho mỗi kịch bản tính toán là 30 giây.

Điều kiện biên của mô hình chất lượng nước khu vực đầm Thị Nại: Dựa theo các kêt quả phân tích hàm lượng các nhóm chất trong thời gian khảo sát.

Điều kiện ban đầu: Là giá trị trung bình hàm lượng các chất cần được tính toán, mô phỏng. Sau đó, điều kiện ban đầu của mô hình được lấy từ kết quả của lần chạy trước đó của mô hình (khoảng thời gian 1 tháng).

Kiểm nghiệm, hiệu chỉnh các tham số tính toán của mô hình: Việc kiểm nghiệm, đánh giá kết quả được thực hiện bằng cách so sánh kết quả của mô hình với các số liệu đo đạc quan trắc ngoài hiện trường và kết quả của các mô hình khác được thực hiện trong quá khứ ở khu vực nghiên cứu. So sánh kết quả tính toán mực nước từ mô hình với mực nước quan trắc tại Quy Nhơn cho thấy khá phù hợp kể cả về pha và biên độ. Sai số bình phương trung bình giữa tính toán và đo đạc mực nước ở các trạm này dao động trong khoảng 0,13 - 0,14 m.

\section{Tính khối lự̛ng hiện tại và dụ báo}

Khối lượng tổng cộng (hiện tại, dự báo, mưa, khô, triều cường, kém):

$$
M=\sum_{\substack{1 \leq i \leq m \\ 1<j<<n}} M(i, j)
$$

Trong đó các khối lượng thành phần (tại các ô lưới $\mathrm{i}, \mathrm{j})$ :

$$
M_{i, j}=C_{i, j} \times V_{i, j}
$$
thức:

Thể tích của các ô lưới được tính theo công

$$
V_{i, j}=h_{i, j} \times A_{i, j}
$$

Trong đó $\mathrm{h}_{\mathrm{ij}}$ là độ sâu của các ô lưới tính thành phần; $\mathrm{A}_{\mathrm{ij}}$ là diện tích các ô lưới thành phần; $\mathrm{C}_{\mathrm{ij}}$ là hàm lượng của mỗi tham số tại mỗi ô lưới (i, j) thành phần.

Các giá trị: $\mathrm{h}_{\mathrm{ij}}, \mathrm{A}_{\mathrm{ij}}, \mathrm{C}_{\mathrm{ij}}$ tính theo mô hình với các kịch bản khác nhau (hiện tại, dự báo, mùa mưa, mùa khô, kỳ triều cường kém).

Các kịch bản tính toán dụ báo 
Nhằm đánh giá dự báo chất lượng môi trường nước ở khu vực đầm Thị Nại, chúng tôi căn cứ trên các kết quả dự báo về tải lượng thải do các hoạt động kinh tế xã hội vào khu vực đầm Thị Nại [7]. Theo các kết quả dự báo đó, đến năm 2025 lượng chất hữu cơ và dinh dưỡng hòa tan đưa vào đầm Thị Nại sẽ có biến động khác nhau: trong khi các lượng COD tăng lên khoảng $10 \%$, BOD giảm 30\%, TSS giảm $40 \%$, thì dinh dưỡng hòa tan tăng khoảng 50$70 \%$ so với hiện tại.

Tính khối lượng nguõng cho phép theo quy chuẩn

$$
V_{q c}=C_{q c} \times V_{t b}
$$

Trong đó: $\mathrm{M}_{\mathrm{qc}}$ - ngưỡng khối lượng thủy vực có thể chứa được tối đa theo quy chuẩn; $\mathrm{C}_{\mathrm{qc}}{ }^{-}$ Ngưỡng giới hạn cho phép; $\mathrm{V}_{\mathrm{tb}}$ - thể tích trung bình của thủy vực. Ngưỡng giới hạn cho phép được lấy theo các tiêu chuẩn của Việt Nam và Asean (bảng 1). Thể tích trung bình của đầm: Mùa mưa: 88,43 triệu $\mathrm{m}^{3}$ - triều cường; 89,57 triệu $\mathrm{m}^{3}$ - triều kém; Mùa khô: 86,53 triệu $\mathrm{m}^{3}$ triểu cường; 86,91 triệu $\mathrm{m}^{3}$ - triều kém.

Bảng 1. Tiêu chuẩn chất lượng nước của các thông số tính toán

\begin{tabular}{|c|c|c|c|c|}
\hline TT & Thông số & Đơn vị & Giá trị & Tiêu chuẩn \\
\hline 1 & COD & $\mathrm{mg} / \mathrm{l}$ & 15 & XCVN 08:2008 [23] \\
\hline 2 & $\mathrm{BOD}_{5}$ & $\mathrm{mg} / \mathrm{l}$ & 6 & QCVN 08:2008 \\
\hline 3 & $\mathrm{NH}_{3,4}($ tính theo $\mathrm{N})$ & $\mathrm{mg} / \mathrm{l}$ & 0,1 & QCVN10:2008 [24] \\
\hline 4 & $\mathrm{NO}_{3}^{-}$(tính theo $\mathrm{N}$ ) & $\mathrm{mg} / \mathrm{l}$ & 0,060 & Asean 2008 [25] \\
\hline 5 & $\mathrm{PO}_{4}$ (tính theo $\mathrm{P}$ ) & $\mathrm{mg} / \mathrm{l}$ & 0,045 & Asean 2008 \\
\hline 6 & TSS & $\mathrm{mg} / \mathrm{l}$ & 50 & QCVN 10:2008 \\
\hline 7 & $\mathrm{Cu}$ & $\mathrm{mg} / \mathrm{l}$ & 0,03 & QCVN 10:2008 \\
\hline 8 & $\mathrm{~Pb}$ & $\mathrm{mg} / \mathrm{l}$ & 0,05 & QCVN 10:2008 \\
\hline 9 & $\mathrm{Zn}$ & $\mathrm{mg} / \mathrm{l}$ & 0,05 & QCVN 10:2008 \\
\hline 10 & $\mathrm{Hg}$ & $\mathrm{mg} / \mathrm{l}$ & 0,001 & QCVN 10:2008 \\
\hline 11 & As & $\mathrm{mg} / \mathrm{l}$ & 0,01 & QCVN 10:2008 \\
\hline 12 & $\mathrm{Cd}$ & $\mathrm{mg} / \mathrm{l}$ & 0,005 & QCVN 10:2008 \\
\hline
\end{tabular}

\section{KẾT QUẢ NGHIÊN CÚU}

Tính toán khả năng tiếp nhận chất ô nhiễm ở thời điểm hiện tại

Tính toán tổng lựng chất gây ô nhiễm trong nước biển

Kết quả tính toán tổng khối lượng các chất hữu cơ và dinh dưỡng trong nước đầm Thị Nại theo mùa được trình bày trong bảng 2 . Các số liệu trong bảng này cho thấy rằng vào những thời điểm khác nhau tổng lượng chất gây ô nhiễm trong nước đầm Thị Nại cũng khác nhau, có sự biến động giữa kỳ triều cường và kỳ triều kém. Vào kỳ triều kém, mùa mưa, lượng chất ô nhiễm trong đầm có giá trị lớn nhất, ngược lại vào kỳ triều cường, mùa khô, lượng chất ô nhiễm trong đầm có giá trị nhỏ nhất.

Bảng 2. Khối lượng chất gây ô nhiễm (tấn) trong nước đầm Thị Nại vào mùa mưa (tháng 10/2013) và mùa khô (tháng 5/2014)

\begin{tabular}{|c|c|c|c|c|c|}
\hline \multirow{2}{*}{$\begin{array}{c}\text { Thông } \\
\text { số }\end{array}$} & \multicolumn{2}{|c|}{ Mùa mưa } & \multicolumn{2}{|c|}{ Mùa khô } & \multirow{2}{*}{$\begin{array}{c}\text { Trung } \\
\text { bình }\end{array}$} \\
\hline & $\begin{array}{l}\text { Triều } \\
\text { cường }\end{array}$ & $\begin{array}{l}\text { Triều } \\
\text { kém }\end{array}$ & $\begin{array}{l}\text { Triều } \\
\text { cường }\end{array}$ & $\begin{array}{l}\text { Triều } \\
\text { kém }\end{array}$ & \\
\hline COD & 720 & 758,8 & 544,8 & 596 & 654,9 \\
\hline $\mathrm{BOD}_{5}$ & 360,7 & 375,4 & 217,1 & 231,6 & 296,2 \\
\hline $\mathrm{N}-\mathrm{NH}_{3,4}$ & 12,8 & 13,3 & 10,3 & 10,7 & 11,775 \\
\hline $\mathrm{N}-\mathrm{NO}_{3}^{-}$ & 26,8 & 28,3 & 18,2 & 19 & 23,075 \\
\hline $\mathrm{P}-\mathrm{PO}_{4}$ & 4,6 & 4,7 & 3,2 & 3,5 & 4,0 \\
\hline TSS & 4783 & 4530,2 & 2343,4 & 2416,3 & 3518,2 \\
\hline $\mathrm{Cu}$ & 0,50002 & 0,51993 & 0,05642 & 0,05251 & 0,2822 \\
\hline $\mathrm{Pb}$ & 0,2273 & 0,3035 & 0,0069 & 0,0826 & 0,1551 \\
\hline $\mathrm{Zn}$ & 2,36880 & 2,46863 & 1,79240 & 1,66874 & 2,0746 \\
\hline $\mathrm{Hg}$ & 0,0057 & 0,0073 & 0,0011 & 0,0027 & 0,0042 \\
\hline As & 0,0386 & 0,0590 & 0,0159 & 0,0219 & 0,0338 \\
\hline $\mathrm{Cd}$ & 0,0228 & 0,0304 & 0,0002 & 0,0078 & 0,0153 \\
\hline
\end{tabular}

Tính toán, đánh giá khả năng tiếp nhận chất gây ô nhiếm

Để đánh giá khả năng tiếp nhận thêm các chất gây ô nhiễm, cần biết được khối lượng tối đa của chất ô nhiềm có trong nước mà không vi phạm tiêu chuẩn môi trường. Khối lượng này được tính trong bảng 3 .

Bảng 3. Tổng lượng chất gây ô nhiễm tối đa (tấn) mà đầm Thị Nại được phép có trong nước theo các tiêu chuẩn môi trường

\begin{tabular}{|c|c|c|c|c|c|}
\hline \multirow{2}{*}{$\begin{array}{c}\text { Thông } \\
\text { số }\end{array}$} & \multicolumn{2}{|c|}{ Mùa mưa } & \multicolumn{2}{|c|}{ Mùa khô } & \multirow{2}{*}{$\begin{array}{c}\text { Trung } \\
\text { bình }\end{array}$} \\
\hline & $\begin{array}{c}\text { Triều } \\
\text { cường }\end{array}$ & $\begin{array}{l}\text { Triều } \\
\text { kém }\end{array}$ & $\begin{array}{l}\text { Triều } \\
\text { cường }\end{array}$ & $\begin{array}{l}\text { Triều } \\
\text { kém }\end{array}$ & \\
\hline COD & 1326,5 & 1343,6 & 1297,9 & 1303,6 & 1317,9 \\
\hline $\mathrm{BOD}_{5}$ & 530,6 & 537,4 & 519,2 & 521,4 & 527,15 \\
\hline $\mathrm{N}-\mathrm{NH}_{3,4}$ & 8,85 & 8,95 & 8,65 & 8,7 & 8,79 \\
\hline $\mathrm{N}-\mathrm{NO}_{3}-$ & 6,2 & 6,3 & 6,1 & 6,1 & 6,175 \\
\hline $\mathrm{P}-\mathrm{PO}_{4}$ & 4 & 4 & 3,9 & 3,9 & 3,95 \\
\hline TSS & 4421,5 & 4478,6 & 4326,4 & 4345,4 & 4393,0 \\
\hline $\mathrm{Cu}$ & 2,6529 & 2,6872 & 2,5958 & 2,6072 & 2,6358 \\
\hline $\mathrm{Pb}$ & 4,4215 & 4,4786 & 4,3264 & 4,3454 & 4,3930 \\
\hline $\mathrm{Zn}$ & 4,4215 & 4,4786 & 4,3264 & 4,3454 & 4,3930 \\
\hline $\mathrm{Hg}$ & 0,0884 & 0,0896 & 0,0865 & 0,0869 & 0,0879 \\
\hline As & 0,8843 & 0,8957 & 0,8653 & 0,8691 & 0,8786 \\
\hline $\mathrm{Cd}$ & 0,4422 & 0,4479 & 0,4326 & 0,4345 & 0,4393 \\
\hline
\end{tabular}


Trên cơ sở của các bảng 2 và 3 , có thể tính được tổng lượng chất ô nhiê̂m mà đầm Thị Nại có thể tiểp nhận được để không vi phạm các tiêu chuẩn môi trường (bảng 4).

Bảng 4. Khả năng tiếp nhận hiện tại (tấn) của đầm Thị Nại mà không gây ô nhiềm theo các tiêu chuẩn môi trường

\begin{tabular}{|c|c|c|c|c|c|}
\hline \multirow{2}{*}{$\begin{array}{c}\text { Thông } \\
\text { số }\end{array}$} & \multicolumn{2}{|c|}{ Mùa mưa } & \multicolumn{2}{|c|}{ Mùa khô } & \multirow{2}{*}{$\begin{array}{c}\text { Trung } \\
\text { bình }\end{array}$} \\
\hline & $\begin{array}{c}\text { Triều } \\
\text { cường }\end{array}$ & $\begin{array}{l}\text { Triều } \\
\text { kém }\end{array}$ & $\begin{array}{c}\text { Triều } \\
\text { cường }\end{array}$ & $\begin{array}{l}\text { Triều } \\
\text { kém }\end{array}$ & \\
\hline COD & 606,5 & 584,8 & 753,1 & 707,6 & 663,0 \\
\hline $\mathrm{BOD}_{5}$ & 169,9 & 162 & 302,1 & 289,8 & 231,0 \\
\hline $\mathrm{N}-\mathrm{NH}_{3,4}$ & $-3,95$ & $-4,35$ & $-1,65$ & $-2,0$ & $-2,99$ \\
\hline $\mathrm{N}-\mathrm{NO}_{3}-$ & $-20,6$ & -22 & $-12,1$ & $-12,9$ & $-16,9$ \\
\hline $\mathrm{P}-\mathrm{PO}_{4}$ & $-0,6$ & $-0,7$ & 0,7 & 0,4 & $-0,1$ \\
\hline TSS & $-361,5$ & $-51,6$ & 1983 & 1929,1 & 874,8 \\
\hline $\mathrm{Cu}$ & 2,1529 & 2,1672 & 2,5394 & 2,5547 & 2,3536 \\
\hline $\mathrm{Pb}$ & 4,1942 & 4,1751 & 4,3195 & 4,2628 & 4,2379 \\
\hline $\mathrm{Zn}$ & 2,0527 & 2,0100 & 2,5340 & 2,6767 & 2,3183 \\
\hline $\mathrm{Hg}$ & 0,0827 & 0,0823 & 0,0854 & 0,0842 & 0,0837 \\
\hline As & 0,8457 & 0,8367 & 0,8494 & 0,8472 & 0,8448 \\
\hline $\mathrm{Cd}$ & 0,4194 & 0,4175 & 0,4324 & 0,4268 & 0,4240 \\
\hline
\end{tabular}

Bảng 4 cho thấy, vào mùa mưa, đầm Thị Nại có thể tiếp nhận 595,65 tấn COD, 165,95 tân $\mathrm{BOD}_{5}, 2,16$ tân $\mathrm{Cu}, 4,18$ tấn $\mathrm{Pb}, 2,03$ tấn $\mathrm{Zn}, 0,083$ tấn $\mathrm{Hg}, 0,84$ tấn $\mathrm{As}$ và 0,42 tấn $\mathrm{Cd}$. Đầm Thị Nại không có khả năng tiếp nhận $\mathrm{NH}_{4,3}, \mathrm{NO}_{3}, \mathrm{PO}_{4}$ và TSS vào mùa mưa. Vào mùa khô khả năng tiếp nhận của đầm Thị Nại là 730,35 tấn COD, 295,95 tấn $\mathrm{BOD}_{5}, 0,55$ tấn $\mathrm{PO}_{4}, 1956$ tấn TSS, 2,55 tấn $\mathrm{Cu}, 4,29$ tấn $\mathrm{Pb}$, 2,60 tấn $\mathrm{Zn}, 0,085$ tấn $\mathrm{Hg}, 0,85$ tấn As và 0,43 tấn $\mathrm{Cd}$. Đầm Thị Nại không có khả năng tiếp nhận $\mathrm{NH}_{3,4}, \mathrm{NO}_{3}$ trong cả mùa mưa và mùa khồ. So sánh giữa 2 mùa nhận thấy, khả năng tiếp nhận của đầm Thị Nại cao hơn vào mùa khô ở hầu hết các thông số đặc biệt đối với TSS và $\mathrm{PO}_{4}$. Trong cùng một mùa thì khả năng tiếp nhận cao vào kỳ triều cường và thấp vào kỳ triều kém do trong kỳ triều cường khả năng trao đổi nước lớn hơn nên khả năng lưu giữ chất thấp hơn.

Các kết quả phân tích cũng cho thấy, nước đầm Thị Nại đã bị nhiễm bẩn amoni và nitrat khi so sánh với tiêu chuẩn nước biển ven bờ của Việt Nam và ASEAN. Các chỉ tiêu TSS và phosphate cũng bị nhiễm bẩn trong mùa mưa nhưng mức độ thấp hơn.

Dự báo khả năng tiếp nhận các chất gây ô nhiếm năm 2025
Tính toán tổng lương chất ô nhiễm có trong nước năm 2025

Các bảng 5 và bảng 6 trình bày lượng chất ô nhiễm trong khối nước và khả năng tiếp nhận của chúng tại đầm Thị Nại đến năm 2025. So sánh với các kịch bản hiện trạng thì thấy rằng, tới năm 2025, lượng chất ồ nhiễm tích lũy trong khối nước tăng lên, khả năng tiếp nhận của thủy vực giảm đi và một số thông số $\left(\mathrm{NH}_{3,4}, \mathrm{NO}_{3}, \mathrm{PO}_{4}\right)$ không còn khả năng tiếp nhận nữa.

Bảng 5. Khối lượng chất gây ô nhiễm (tấn) trong nước đầm Thị Nại năm 2025

\begin{tabular}{|c|c|c|c|c|c|}
\hline \multirow{2}{*}{$\begin{array}{c}\text { Thông } \\
\text { số }\end{array}$} & \multicolumn{2}{|c|}{ Mùa mưa } & \multicolumn{2}{|c|}{ Mùa khô } & \multirow{2}{*}{$\begin{array}{l}\text { Trung } \\
\text { bình }\end{array}$} \\
\hline & $\begin{array}{c}\text { Triều } \\
\text { cường }\end{array}$ & $\begin{array}{l}\text { Triều } \\
\text { kém }\end{array}$ & $\begin{array}{c}\text { Triều } \\
\text { cường }\end{array}$ & $\begin{array}{l}\text { Triều } \\
\text { kém }\end{array}$ & \\
\hline COD & 748,8 & 790,5 & 560,6 & 790,5 & 722,6 \\
\hline $\mathrm{BOD}_{5}$ & 280,2 & 285,7 & 150,5 & 285,7 & 250,525 \\
\hline $\mathrm{N}-\mathrm{NH}_{3,4}$ & 16,7 & 17,1 & 13,1 & 17,1 & 16 \\
\hline $\mathrm{N}-\mathrm{NO}_{3-}^{-}$ & 35,5 & 36,9 & 24,1 & 36,9 & 33,35 \\
\hline $\mathrm{P}-\mathrm{PO}_{4}$ & 6,9 & 7,1 & 4,8 & 7,1 & 6,475 \\
\hline TSS & 3926,4 & 3824,2 & 1974,7 & 2093,3 & 2954,6 \\
\hline $\mathrm{Cu}$ & 0,5750 & 0,5980 & 0,0649 & 0,5980 & 0,4590 \\
\hline $\mathrm{Pb}$ & 0,2275 & 0,3037 & 0,0083 & 0,0840 & 0,1559 \\
\hline $\mathrm{Zn}$ & 2,6241 & 2,7839 & 2,0613 & 1,9590 & 2,3517 \\
\hline $\mathrm{Hg}$ & 0,0046 & 0,0072 & 0,0012 & 0,0028 & 0,0040 \\
\hline As & 0,0444 & 0,0626 & 0,0173 & 0,0266 & 0,0377 \\
\hline $\mathrm{Cd}$ & 0,0228 & 0,0304 & 0,0002 & 0,0078 & 0,0153 \\
\hline
\end{tabular}

Bảng 6. Khả năng tiếp nhận dự báo 2025 (tấn) của đầm Thị Nại mà không gây ô nhiễm theo các tiêu chuẩn môi trường

\begin{tabular}{|c|c|c|c|c|c|}
\hline \multirow{2}{*}{$\begin{array}{c}\text { Thông } \\
\text { số }\end{array}$} & \multicolumn{2}{|c|}{ Mùa mưa } & \multicolumn{2}{|c|}{ Mùa khô } & \multirow{2}{*}{$\begin{array}{c}\text { Trung } \\
\text { bình }\end{array}$} \\
\hline & $\begin{array}{c}\text { Triều } \\
\text { cường }\end{array}$ & $\begin{array}{l}\text { Triều } \\
\text { kém }\end{array}$ & $\begin{array}{c}\text { Triều } \\
\text { cường }\end{array}$ & $\begin{array}{l}\text { Triều } \\
\text { kém }\end{array}$ & \\
\hline COD & 577,7 & 553,1 & 737,3 & 692,7 & 640,2 \\
\hline $\mathrm{BOD}_{5}$ & 250,4 & 251,7 & 368,7 & 355,8 & 306,65 \\
\hline $\mathrm{N}-\mathrm{NH}_{3,4}$ & $-7,85$ & $-8,15$ & $-4,45$ & $-8,4$ & $-7,21$ \\
\hline $\mathrm{N}-\mathrm{NO}_{3}^{-}$ & $-29,3$ & $-30,6$ & -18 & $-19,1$ & $-24,25$ \\
\hline $\mathrm{P}-\mathrm{PO}_{4}$ & $-2,9$ & $-3,1$ & $-0,9$ & -1 & $-1,975$ \\
\hline TSS & 495,1 & 654,4 & 2351,7 & 2252,1 & 1438,3 \\
\hline $\mathrm{Cu}$ & 2,0779 & 2,0892 & 2,5309 & 2,5427 & 2,3102 \\
\hline $\mathrm{Pb}$ & 4,1940 & 4,1749 & 4,3181 & 4,2614 & 4,2371 \\
\hline $\mathrm{Zn}$ & 1,7974 & 1,6947 & 2,2651 & 2,3864 & 2,0359 \\
\hline $\mathrm{Hg}$ & 0,0838 & 0,0824 & 0,0853 & 0,0841 & 0,0839 \\
\hline As & 0,8399 & 0,8331 & 0,8480 & 0,8425 & 0,8409 \\
\hline $\mathrm{Cd}$ & 0,4194 & 0,4175 & 0,4324 & 0,4267 & 0,4240 \\
\hline
\end{tabular}

Bảng 6 cho thấy, tới năm 2025, vào mùa mưa, đầm Thị Nại có thể tiếp nhận 564,4 tấn COD, 251,05 tấn $\mathrm{BOD}_{5}, 574,75$ tấn TSS, 2,08 tấn $\mathrm{Cu}, 4,18$ tấn $\mathrm{Pb}, 1,74$ tấn $\mathrm{Zn}, 0,083$ tấn $\mathrm{Hg}$, 0,84 tấn $\mathrm{As}$ và 0,43 tấn $\mathrm{Cd}$. Đầm Thị Nại không 
có khả năng tiếp nhận $\mathrm{NH}_{3,4}, \mathrm{NO}_{3}$ và $\mathrm{PO}_{4}$ vào mùa mưa. Vào mùa khô khả năng tiếp nhận của đầm Thị Nại là 715 tấn COD, 362,3 tấn $\mathrm{BOD}_{5}$, 2301,9 tấn TSS, 2,54 tấn $\mathrm{Cu}, 4,30$ tấn $\mathrm{Pb}, 2,33$ tấn $\mathrm{Zn}, 0,085$ tấn $\mathrm{Hg}, 0,85$ tấn $\mathrm{As}$ và 0,43 tấn $\mathrm{Cd}$. Đầm Thị Nại không có khả năng tiếp nhận $\mathrm{NH}_{3,4}, \mathrm{NO}_{3}$ và $\mathrm{PO}_{4}$ vào mùa khô. Kết quả tính toán dự báo vẫn thể hiện xu hướng chung là khả năng tiếp nhận cao hơn vào mùa khô, thời điểm triểu cường có thể tiếp nhận nhiều hơn thời điểm triều kém.

So sánh khả năng tích lũy và tiếp nhận hiện tại và dự báo 2025 thấy là: (1) Khả năng tiếp nhận giảm đi $3,4 \%$ và $12,18 \%$ đối với COD và Zn, theo thứ tự; (2) Khả năng tiếp nhận tăng lên $32,78 \%$ và $64 \%$ đối với $\mathrm{BOD}_{5}$ và TSS và (3) Không cải thiện được khả năng tiếp nhận của $\mathrm{NH}_{3,4}, \mathrm{NO}_{3}, \mathrm{PO}_{4}$ và $\mathrm{Cd}$.

\section{KẾT LUẬN}

Kết quả tính toán lượng chất và khả năng tiếp nhận chất ô nhiễm trong đầm Thị Nại bằng mô hình Delft3D cho thấy, hiện tại đầm Thị Nại đã không còn khả năng tiếp nhận amoni và nitrat; khả năng tiếp nhận của đầm đối với phosphate và TSS thấp. Dự báo đến năm 2025, mặc dù đã tính đến việc triển khai các quy hoạch bảo vệ môi trường trong khu vực nhưng khả năng tiếp nhận của đầm đều giảm đi hoặc cải thiện không đáng kể đối với các thông số chất lượng nước, trừ $\mathrm{BOD}_{5}$ và $\mathrm{TSS}$.

Kết quả tính toán cho thấy cần phải kiểm soát tốt các nguồn thải ven đầm Thị Nại nếu không chất lượng nước đầm sẽ bị suy thoái.

Lò̀i cảm ơn: Các tác giả xin cảm ơn chủ nhiệm đề tài KC09.17/11-15 "Đánh giá sức tải môi trường của một số thủy vực tiêu biểu ven bờ biển Việt Nam phục vụ phát triển bền vững" do Viện Tài nguyên và Môi trường biển thực hiện đã cho phép sử dụng số liệu.

\section{TÀI LIỆU THAM KHẢO}

1. www.tapchikhoahoc.vn. Ô nhiễm ở Trung Quốc ở mức báo động. Cập nhật ngày 7/6/2014.

2. Enhui Liao, E., Jiang, Y., Yan, X. H., Chen, Z., Wang, J., and Zhang, L., 2013. Allocation of marine environmental carrying capacity in the Xiamen bay. Marine Pollution Bulletin, 75(1): 21-27.

3. Li, K., Shi, X., Bao, X., Ma, Q., and Wang, $X$. 2014. Modeling total maximum allocated loads for heavy metals in Jinzhou bay, China. Marine pollution bulletin, 85(2): 659-664.

4. Wang, S., Xu, L., Yang, F., and Wang, H., 2014. Assessment of water ecological carrying capacity under the two policies in Tieling City on the basis of the integrated system dynamics model. Science of The Total Environment, 472, 1070-1081.

5. Zhao, W. L., Yang, S. Y., Wang, J., Xiao, J. M., Lu, X. X., Lin, J., Huang, P., and Cai, $M$. G., 2015. Load estimation and assessment of land-based pollution for Quanzhou Bay and their relevance to the Total Quantity Control of Pollutants Discharged into the Sea (TQCPS) Program in China. Estuarine, Coastal and Shelf Science, 166, 230-239.

6. Zhao, L., Zhang, X., Liu, Y., He, B., Zhu, X., Zou, R., and Zhu, Y., 2012. Threedimensional hydrodynamic and water quality model for TMDL development of Lake Fuxian, China. Journal of Environmental Sciences, 24(8): 1355-1363.

7. Le Xuan Sinh, Le Van Nam, Luu Van Dieu, Cao Thi Thu Trang, Nguyen Thi Phuong Hoa, Tran Duc Thanh, 2015. Assessment of Pollution Load into Thi Nai lagoon, Vietnam and Prediction to 2025. International Journal of Sciences, 4, 116127.

8. Lê Thi Vinh, Nguyến Thị Thanh Thuỷ, 2011. Ảnh hưởng của các nguồn thải đển môi trường nước đầm Thị Nại. Tạp chí Khoa học và Công nghệ biển, 11(4): 35-46.

9. Lê Thị Vinh, Nguyễn Thị Thanh Thuỷ, 2009. Một số vẫn đề liên quan đến chất lượng mồi trường nước đầm Thị Nại, tỉnh Bình Định. Hội thảo "Khoa học công nghệ, môi trường và phát triển bền vững ở duyên hải miền Trung", Tr. 196-205.

10. Lê Thị Vinh, 2015. Chất lượng môi trường nước tại các đầm từ Bình Định đến Ninh Thuận trong thời gian gần đây. Tạp chí 
Tính toán khả năng tiếp nhận chất ô nhiễm ...

Khoa học và Công nghệ biển, 15(2): 176184.

11. Thu, T. C. T., Van, D. L., Duc, T. T., and Le Xuan, S., 2015. Assessment of SelfPurification Process of Thi Nai lagoon (Binh Dinh Province, Viet Nam). Environment and Natural Resources Research, 5(3): 19.

12. Lê Thị Vinh, Nguyễn Thị Thanh Thuỷ, Tống Phước Hoàng Sơn, Dương Trọng Kiểm, Nguyễn Hồng Thu, Pham Hũu Tâm, Phạm Hồng Ngoc, 2010. Chất lượng môi trường trầm tích đầm Thị Nại, tỉnh Bình Định. Tạp chí Khoa học và Công nghệ biển, 10(4): 113.

13. Nguyễn Thị Thanh Thuỷ, Lê Thị Vinh, Võ Sĩ Tuấn, 2011. Một số vấn đề kinh tế xã hội và môi trường đầm Thị Nại, Bình Định các giải pháp quản lý tổng hợp vùng đầm. Hội nghị Khoa học và Công nghệ biển toàn quốc lần thứ $\mathrm{V}$. Nxb. Khoa học Tự nhiên và Công nghệ. Tr. 449-456

14. Cao Thị Thu Trang, Lưu Văn Diệu, Lê Xuân Sinh, Trần Đức Thạh, 2015. Năng suất sơ cấp khu vực đầm Thị Nại (tỉnh Bình Định). Tạp chí Khoa học và Công nghệ biển, 15(2): 185-192.

15. Đặng Hoài Nhơn, Nguyễn Thị Kim Anh, Nguyễn Hưu Cư, 2010. Các chất ô nhiễm trong trầm tích tầng mặt các đầm phá ven bờ Việt Nam. Tạp chí Khoa học và Công nghệ, 48(2A): 804-814.

16. Đặng Hoài Nhơn, Nguyễn Thì Kim Anh, Nguyến Hũu Củ, 2011. Đặc điểm trầm tích và dinh dưỡng trong trầm tích tầng mặt đầm phá miền Trung Việt Nam. Tuyển tập Tài nguyên và Môi trường biển. Tập XVI. Tr. 47-58. ISBN: 978-604-913-074-8.

17. Becker, J. J., Sandwell, D. T., Smith, W. H. F., Braud, J., Binder, B., Depner, J., Fabre, D., Factor, J., Ingalls, S., Kim, S-H., Ladner, R., Marks, K., Nelson, S., Pharaoh,
A., Trimmer, R., Von Rosenberg, J., Wallace, G., Weatherall, P., 2009. Global bathymetry and elevation data at 30 arc seconds resolution: SRTM30_PLUS. Marine Geodesy, 32(4): 355-371.

18. Jones, M. T., Weatherall, P., and Cramer, $R$. N., 2009. User guide to the Centenary Edition of the GEBCO Digital Atlas and its data sets. Natural Environment Research Council.

19. World Ocean Atlas, 2009. National Oceanographic Data Center. 30-03-2010. http://www.nodc.noaa.gov/OC5/WOA09/pr _woa09.html. Retrieved 19-5-2010.

20. Lefevre, F., Lyard, F. H., Le Provost, C., and Schrama, E. J., 2002. FES99: a global tide finite element solution assimilating tide gauge and altimetric information. Journal of Atmospheric and Oceanic Technology, 19(9): 1345-1356.

21. Lyard, F., Lefevre, F., Letellier, T., and Francis, O., 2006. Modelling the global ocean tides: modern insights from FES2004. Ocean Dynamics, 56(5-6): 394415.

22. WL Delft Hydraulics, 1999. Delft3DFLOW User Manual Version 3.05, Delft3D-Waq User Manual Version 3.01, Delft3D-Part User Manual Version 1.0 WL| Delft Hydraulics, Delft, The Netherlands.

23. Bộ Tài nguyên và Môi trường, 2008. Quy chuẩn kỹ thuật quốc gia về chất lượng nước biển ven bờ (QCVN 10:2008/BTNMT).

24. Bộ Tài nguyên và Môi trường, 2008. Quy chuẩn kỹ thuật quốc gia về chất lượng nước mặt (QCVN 08:2008/BTNMT).

25. Secretariat, A. S. E. A. N., 2008. ASEAN Marine Water Quality Management Guidelines and Monitoring Manual. Australia Marine Science and Technology Ltd.(AMSAT), Australia. 


\title{
CALCULATION OF RECEIVING CAPACITY OF POLLUTANTS IN THI NAI LAGOON (BINH DINH PROVINCE)
}

\author{
Cao Thi Thu Trang, Vu Duy Vinh
}

Institute of Marine Environment and Resources-VAST

\begin{abstract}
Based on the surveys at Thi Nai lagoon in rainy season (October, 2013) and dry season (May, 2014) and the documents on natural conditions, socio-economic status of Thi Nai lagoon, receiving capacity of pollutants in the lagoon was calculated on the basis of environmental standards, using Delft3D model. Calculation results showed that at present Thi Nai lagoon no longer has capacity to receive ammonium and nitrate. Until 2025, besides two parameters, Thi Nai lagoon will no longer have capacity to receive phosphate. In addition, the receiving capacity of the lagoon will be reduced for most of parameters while receiving capacity of lagoon for $\mathrm{BOD}_{5}$ and TSS will increase. Regarding heavy metals, receiving capacity of lagoon will be reduced, especially for $\operatorname{Zn}(12.18 \%)$.
\end{abstract}

Keywords: Pollutant mass, receiving capacity, Thi Nai lagoon. 